\title{
HIV STATUS DISCLOSURE AMONG INFECTED MEN WHO HAVE SEX WITH MEN (MSM) IN BUENOS AIRES, ARGENTINA
}

\author{
Alex Carballo-Diéguez, Iván C. Balán, Curtis Dolezal, \\ Mobolaji Ibitoye, María A. Pando, Rubén Marone, \\ Victoria Barreda, and María Mercedes Ávila
}

Five hundred men who have sex with men were recruited in Buenos Aires using respondent driven sampling. Of them, 46 respondents ( 24 of them not gay identified) who were HIV infected were asked questions on serodisclosure. The sample was characterized by indicators of low socioeconomic status. Most of the respondents reported being in good to excellent health despite $42 \%$ of them having been diagnosed with AIDS. Only $10 \%$ of respondents had not disclosed their serostatus to at least one person. Coworkers and lovers or main sexual partners were those most likely to know the respondents' serostatus. Reactions to disclosure were for the most part supportive. Those who had not disclosed anticipated less favorable reactions than those who had disclosed. No significant differences were observed between gay and non-gay identified respondents. The progressive social environment of Argentina that includes federal laws recognizing gay marriage may contribute to create a climate favorable for serostatus disclosure.

\section{INTRODUCTION}

HIV status disclosure plays a major role in reducing HIV transmission and has been identified as an important target for public health HIV prevention efforts (Bird \&

\footnotetext{
Alex Carballo-Diéguez, Ph.D., Iván C. Balán, Ph.D., Curtis Dolezal, Ph.D., and Mobolaji Ibitoye, MPH, are affiliated with the HIV Center for Clinical and Behavioral Studies, New York State Psychiatric Institute and Columbia University, New York, New York. María A. Pando, Ph.D., and María Mercedes Ávila, Ph.D., are affiliated with Centro Nacional de Referencia para el SIDA, Departamento de Microbiología, Parasitología e Inmunología, Facultad de Medicina, Universidad de Buenos Aires, Buenos Aires, Argentina. Rubén Marone, Lic., and Victoria Barreda, Lic., are with Nexo Asociación Civil, Buenos Aires, Argentina.

This study was supported with funds from the US National Institute of Mental Health to the HIV Center for Clinical and Behavioral Studies at the New York State Psychiatric Institute and Columbia University (R01 MH073410; Principal Investigator: Alex Carballo-Diéguez, Ph.D.). Additional funds came from a grant from the U.S. National Institute of Mental Health to the HIV Center for Clinical and Behavioral Studies at New York State Psychiatric Institute and Columbia University (P30-MH43520; Principal Investigator: Anke A. Ehrhardt, Ph.D.). The content is solely the responsibility of the authors and does not necessarily represent the official views of NIMH or the NIH.

Address correspondence to Alex Carballo-Diéguez, Ph.D., Unit 15, New York State Psychiatric Institute, 1051 Riverside Dr., New York, NY 10032. E-mail: ac72@columbia.edu
} 
Voisin, 2011). Disclosure of HIV seropositivity to sexual partners provides them the opportunity to decide whether and how to protect themselves from HIV, and the effects of HIV disclosure on sexual behavior and HIV transmission risk have been well documented (Obermeyer, Baijal, \& Pegurri, 2011; Serovich \& Mosack, 2003). Beyond its role in protecting sexual partners from HIV transmission, HIV status disclosure to family members, loved ones and other members of one's social network can also have several positive consequences for people living with HIV (PLWH). Benefits of disclosure include receipt of social support, a feeling of relief and improved mood state, lower likelihood of depression, increased self-esteem, improved physical and mental health, ability to openly seek HIV treatment, better engagement and retention in HIV care, and increased treatment adherence (Obermeyer et al., 2011; Serovich, 2001; Stirratt et al., 2006; Waddell \& Messeri, 2006; Wohl et al., 2011; Woodward \& Pantalone, 2012; Zea, Reisen, Poppen, Bianchi, \& Echeverry, 2005, 2007).

However, serostatus disclosure is often very challenging for PLWH (Bairan et al., 2007; Kalichman, DiMarco, Austin, Luke, \& DiFonzo, 2003; Serovich, Grafsky, \& Craft, 2011). In deciding whether or not to disclose their seropositivity, PLWH often take into account the effect of the disclosure not just on themselves, but also on the people to whom they disclose (Mason, Marks, Simoni, Ruiz, \& Richardson, 1995; McKay \& Mutchler, 2011; Serovich \& Mosack, 2003). HIV serostatus disclosure decisions are often influenced by various cognitive, cultural, and contextual factors (Bird \& Voisin, 2011; Mason et al., 1995; Nachega et al., 2012), especially by HIV-related stigma (Pulerwitz, Michaelis, Lippman, Chinaglia, \& Diaz, 2008). Seropositivity disclosure can be met with negative reactions such as rejection, verbal abuse, violence or other threatening behavior, as well as stigma-induced responses from members of the PLWH's social network, potential sex partners, family and friends (Kalichman et al., 2003; Obermeyer et al., 2011; Zea, Reisen, Poppen, Echeverry, \& Bianchi, 2004). Therefore, PLWH often weigh the pros and cons of disclosure, and are more likely to disclose their serostatus when they perceive that the positive consequences of disclosure outweigh the negative ones (McKay \& Mutchler, 2011; Serovich, 2001; Zea et al., 2007).

The disclosure decisional process is further complicated for men who have sex with men (MSM), especially those from ethnic minority groups. This is particularly the case for MSM of Latino descent due to the highly stigmatized nature of homosexuality in most Latino cultures (Fekete et al., 2009; Mason et al., 1995; McKay \& Mutchler, 2011). Research conducted in the US shows that Latino MSM may be less likely to disclose their HIV-positive status due to its association with being gay, and gay sexual orientation being stigmatized (Zea et al., 2004). Research has shown that Latino MSM are more likely to disclose their HIV status to members of their social networks who are aware of their sexual orientation (Zea et al., 2004).

Thus, despite the many potential positive consequences of disclosure, HIVpositive Latino MSM are often deterred from disclosing their serostatus due to the anticipated negative reactions of members of their social networks while selectively disclosing serostatus based on anticipated reactions and the quality of relationships (Kalichman et al., 2003; Obermeyer et al., 2011; Serovich, 2001, 2011; Zea et al., 2004, 2005). Latino MSM are more likely to disclose their serostatus to people from whom they anticipate positive reactions (Fekete et al., 2009). This typically includes main sexual partners (especially those of known HIV seropositivity), female relatives, and close friends who are generally expected to react more supportively than 
casual sex partners and male relatives, with close friends being disclosed to more commonly than family members (Fekete et al., 2009; Zea et al., 2004, 2005, 2007).

Our study took place in Argentina, a country whose social attitudes about homosexuality have evolved significantly during the past few decades. Whereas during the time of the military dictatorship homosexuals were targeted for persecution and extortion (Carballo-Diéguez, 1998; Garro, 1993; Pecheny, 2003; Whitam, 1983), in recent years there has been a progressive opening in the discourse about sexual diversity most notably exemplified by the legalization of gay marriage that took place on July 22, 2010. Argentina was the first Latin American country to take this step. Although our recruitment and interviewing took place before the legalization of gay marriage, the social conditions concerning acceptance of homosexuality were significantly advanced at that time. It is therefore significant to study respondents' attitudes about disclosure of HIV status in a city where acceptability of gay men has improved dramatically.

In our study, we explored: (1) disclosure of HIV status among HIV-infected MSM living in Buenos Aires, Argentina; (2) observed or anticipated reactions to disclosure from different members of respondents' social networks; and (3) likelihood of HIV disclosure among those respondents who had not yet done it. The goal of this study was to identify ways to optimize the beneficial correlates of disclosure while minimizing the negative ones.

\section{METHODS}

Ethics Statement. This research study received approval from the Institutional Review Boards of the New York State Psychiatric Institute, New York, NY, USA, and the Comité Independiente de Ética en Investigación de la Facultad de Medicina, Universidad de Buenos Aires, BA, Argentina. Written consent was obtained from all respondents prior to enrollment in the study.

\section{RESPONDENTS}

In order to recruit a diverse sample of MSM, we used respondent driven sampling (RDS), a method that arguably results in more representative samples of hidden populations than convenience sampling (Goel \& Salganik, 2010; Heckathorn, 1997, 2002). Eligibility criteria included to identify as a man, be 18 years or older, have had sex in the prior 6 months with another man or a male-to-female transgender person (TG), have had sex with a man (or men) or TG at least 10 times in his lifetime, reside in the city of Buenos Aires or its suburban areas, have a coupon received from a prior respondent (not applicable to seeds), and agree to provide a blood sample for HIV and STI testing. Both infected and uninfected men could participate in the study. The target recruitment $N$ was 500 respondents.

\section{PROCEDURE}

A detailed description of the use of RDS in this study and its implications has been published elsewhere (Carballo-Diéguez et al., 2011). In brief, 16 seeds were recruited. They underwent all study procedures and were then given three coupons (valid for 60 days) to pass on to members of their networks. All respondents were seen at the offices of Nexo Asociación Civil, a non-governmental organization (NGO) that had been a research partner with the University of Buenos Aires in prior studies. Qualifying respondents underwent an informed consent process with research staff. Subsequently, respondents were taken to a private office in Nexo, 
sat in front of a computer connected to the Internet, and proceeded to respond to a password-protected Web-based computer-assisted self-interview (CASI) that inquired, among other topics, about demographic information, sexual identity, and HIV testing history and, for those stating that they had tested HIV-positive in the past, several additional questions on seropositivity disclosure. This interview lasted about 60 minutes. At the end of the interview, each respondent received the equivalent of 20 United States dollars (USD; at the time, equivalent to the cost of five movie tickets) as compensation for his time. For each referred acquaintance who qualified for the study, regardless of whether he enrolled or not, the respondent received an additional USD 5.

\section{INSTRUMENTS}

Demographics. This questionnaire covered age, education, income, work status, residence, civil status (single, married, divorced, cohabitation with main sexual partner, widow) and health insurance.

Sexual Identity. Respondents were asked if they considered themselves gay/homosexual, bisexual, transvestite (in Buenos Aires, the word transvestite rather than transgender is often used; the category includes both pre- and post-operative individuals), heterosexual, or other (only one choice was possible). The study was not designed to include TG; thus, those identifying as such were deemed ineligible to participate. At the time of the analysis, we compared gay/homosexual vs. non-gay identified respondents.

HIV-Status and Health Status. Respondents were asked whether they were HIVinfected and those who responded affirmatively were asked what their health status had been in the prior two months (excellent, good, poor, very poor). Although respondents were subsequently tested for HIV as part of the study (Pando et al., 2012), for the current analysis focusing on HIV status disclosure prior to study enrollment we decided to focus on respondents with known or assumed HIV positive status without including those who believed they were uninfected but testing found otherwise.

HIV in the Social Network. Respondents were asked in three separate questions, "Of the people close to you, how many do you believe have HIV/have been ill or hospitalized for AIDS/have died of AIDS?" If respondents reported being in couple with a man or a woman, he was asked to report the HIV status of the partner.

HIV Disclosure. Respondents who reported at baseline that they were HIV-infected or assumed to be infected were asked whether they had disclosed their serostatus to family members, lovers/main partners, friends, or co-workers. The original questionnaire included as possible answers: No; No, but I suspect they know; No but they definitely know; and Yes. Given that at the time of data analysis we found that the frequencies in the No, but... categories were too small we decided to group together all the no responses to proceed with the dichotomous analysis included in the tables. Respondents who had disclosed were asked what the reaction was among members in their social environment (Likert scale from $1=$ complete rejection to 10 $=$ complete acceptance). Respondents who had not disclosed were asked what they anticipated the reaction would be among members of their social network (same 
Likert scale) and then how likely they were to disclose their HIV status to each one of them (possible responses being very unlikely, unlikely, likely, very likely, which were dichotomized at the time of analysis).

\section{STATISTICAL ANALYSIS}

All data reported in this study have been weighted based on the RDS II estimator (Salganik \& Heckathorn, 2004; Volz \& Heckathorn, 2008). This approach gives greater weight to respondents with a small personal network size (PNS), since presumably those respondents are less likely to be recruited into the study. Weights were calculated as the inverse of the respondent's PNS. This value was then multiplied by the sample size $(N)$ divided by the sum of weights $(\Sigma \mathrm{w})$. The following weighting formula reflects the original sample size of 500:

$$
(1 / \mathrm{PNS}) \times(\mathrm{N} / \mathrm{\Sigma} \mathrm{w})
$$

Note that when data are weighted, the Ns produced in different analyses are often slightly discrepant. Therefore, the tables report only percentages to avoid confusion over Ns. More details on this analytic strategy are reported elsewhere (CarballoDiéguez et al., 2011). All statistical analyses were conducted using PASW Statistics (Version 18). Gay identified respondents were compared to non-gay identified respondents on demographics and disclosure variables using $t$-tests for continuous variables and chi-square tests for dichotomous variables.

\section{RESULTS}

\section{SAMPLE'S HIV STATUS AND DEMOGRAPHICS}

Of the 500 MSM recruited in the study, 48 reported having tested HIV-positive prior to enrollment. Curiously, 8 of those who reported having tested HIV-positive were found not to be infected when the blood tests were done. Two of the 48 MSM did not provide any disclosure data. Consequently, the rest of our analysis focuses on the 46 MSM who were HIV-positive by self-report for whom we have evaluable data.

Table 1 presents the demographic characteristics of these MSM. It shows that 22 respondents identified as gay whereas 24 did not. Table 1 shows that half of the respondents were in the 36-45 age bracket, a majority had less than complete high school, and the majority also had low monthly income, considering all sources. There was a high level of unemployment and partial employment in the sample. Half of the sample was from the West Zone of Buenos Aires, which is relatively less affluent than the North Zone, from where we were able to recruit very few respondents. Most respondents were single and more than half did not have health insurance. In sum, this was a sample of MSM characterized by indicators of low socioeconomic status.

\section{HEALTH STATUS}

Among the 46 respondents, $46 \%$ reported that their health had been excellent, $51 \%$ that it had been good, $3 \%$ that it had been poor, and none said that it had been very poor in the prior two months. Forty-two percent of infected respondents stated that they had been diagnosed with AIDS. 
TABLE 1. Demographic Characteristics of HIV-Infected MSM Recruited Through RDS (Weighted Values)

\begin{tabular}{|c|c|c|c|}
\hline & Total $(N=46)$ & Gay $(N=22)^{\mathrm{a}}$ & Non-gay $(N=24)^{\mathrm{a}}$ \\
\hline & $\%$ & $\%$ & $\%$ \\
\hline \multicolumn{4}{|l|}{ Age $^{\mathrm{b}}$} \\
\hline $18-25$ & 10 & 8 & 14 \\
\hline $26-35$ & 17 & 19 & 14 \\
\hline $36-45$ & 50 & 50 & 50 \\
\hline $46-55$ & 19 & 15 & 23 \\
\hline $56+$ & 4 & 8 & 0 \\
\hline \multicolumn{4}{|l|}{ Education $^{\mathrm{b}}$} \\
\hline Primary School or Less & 31 & 25 & 38 \\
\hline Incomplete HS & 20 & 21 & 19 \\
\hline Completed HS & 13 & 17 & 10 \\
\hline Some Tertiary Studies & 33 & 33 & 33 \\
\hline University Degree & 2 & 4 & 0 \\
\hline \multicolumn{4}{|l|}{ Monthly Income (in US\$) } \\
\hline None & 19 & 33 & 0 \\
\hline Less than $\$ 286$ & 52 & 28 & 85 \\
\hline$\$ 286-\$ 571$ & 23 & 33 & 8 \\
\hline$\$ 572-\$ 856$ & 3 & 0 & 8 \\
\hline$\$ 857+$ & 3 & 6 & 0 \\
\hline \multicolumn{4}{|l|}{ Work Status ${ }^{c}$} \\
\hline Temporary Work & 22 & 13 & 32 \\
\hline Unemployed & 22 & 33 & 10 \\
\hline Employed by Employer & 26 & 33 & 18 \\
\hline Self Employed & 31 & 21 & 43 \\
\hline Student & 18 & 17 & 19 \\
\hline \multicolumn{4}{|l|}{ Place of Residence $^{d}$} \\
\hline Ciudad Autónoma de Buenos Aires & 39 & 46 & 32 \\
\hline West Zone & 50 & 42 & 59 \\
\hline South Zone & 9 & 13 & 5 \\
\hline North Zone & 2 & 0 & 5 \\
\hline \multicolumn{4}{|l|}{ Civil Status ${ }^{\mathrm{e}}$} \\
\hline Single & 74 & 88 & 59 \\
\hline Married & 13 & 0 & 27 \\
\hline Other & 13 & 13 & 14 \\
\hline \multicolumn{4}{|l|}{ Health Insurance ${ }^{f}$} \\
\hline None & 53 & 42 & 67 \\
\hline "Obra Social" & 36 & 50 & 19 \\
\hline Pre-Paid & 11 & 8 & 14 \\
\hline
\end{tabular}

Notes. ${ }^{a}$ Gay and Non-Gay did not significantly differ on any variables; ${ }^{b}$ Age, education, and monthly income were analyzed as continuous variables (prior to collapsing into categories, if applicable) by t-tests; 'Categories are not mutually exclusive so may sum to more than $100 \%$; "North Zone" was excluded from the Chi-square test, due to low $\mathrm{N}$; " "Married"/"Other" were compared to "Single" in Chi-square test; "Obra social"/"Pre-paid" were compared to "None" in Chi-square test .

\section{HIV IN THE SOCIAL NETWORK}

Eighty-four percent of the infected respondents believed that in their close social network there were other people infected with HIV (range 1-50); 67\% reported that people close to them had been ill or hospitalized due to AIDS (range 1-30), and 67\% reported that they knew people who had died of AIDS (range 1-21).

Among the 46 respondents, 12 reported having a male main sexual partner or lover, six of them being HIV uninfected (i.e., there were six serodiscordant male couples); six respondents reported having a wife or girlfriend, four of them being HIVuninfected (i.e., there were four serodiscordant heterosexual couples); and one respondent reported having a stable relationship with a TG who was HIV-uninfected. Of the 11 respondents who said they had not disclosed their HIV status to their main sexual partner, one reported that the main sexual partner was also HIV infected. 
TABLE 2. Status Disclosure Among HIV Infected Men

\begin{tabular}{lcccccc}
\hline \multirow{2}{*}{ To Whom } & \multicolumn{2}{c}{ Total } & \multicolumn{3}{c}{ Gay } & \multicolumn{2}{c}{ Non-Gay } \\
\cline { 2 - 7 } & $N$ & \% Yes & $N^{1}$ & \% Yes & $N^{1}$ & \% Yes \\
\hline Mother & 39 & 52 & 21 & 57 & 17 & 47 \\
Father & 35 & 41 & 19 & 37 & 17 & 47 \\
Lover or Main Sexual Partner & 40 & 71 & 22 & 82 & 19 & 58 \\
Siblings & 38 & 53 & 20 & 60 & 17 & 47 \\
Other Family & 40 & 75 & 24 & 83 & 17 & 65 \\
Friends & 38 & 32 & 22 & 27 & 16 & 38 \\
Co-workers & 39 & 76 & 21 & 71 & 19 & 79 \\
\hline
\end{tabular}

Note. ${ }^{1} \mathrm{~N}$ varies as some questions are not applicable to all respondents. The sum of the $N$ for Gay and Non-Gay do not always match the total $N$ due to the effects of weighting. Gay and Non-Gay do not significantly differ on any variables.

\section{DISCLOSURE OF HIV STATUS.}

Of the 46 respondents, only 5 had disclosed their status to no one. There were no differences between gay and non-gay identified respondents in terms of the proportions of them likely to disclose to no one, one, two or more people.

Table 2 presents the proportion of respondents who disclosed their HIV-positive status to different members of their social environment. Interestingly, slightly over three quarters of respondents had disclosed their serostatus to past or current coworkers and about the same proportion to main sexual partners. By contrast only slightly over half of respondents had disclosed their status to siblings or mother. No significant differences were observed between gay and non-gay identified respondents in terms of disclosure, although this may be due in part to small sample size. Not included in the tables, we analyzed whether having been diagnosed with AIDS influenced the likelihood of disclosure. In only two cases did we find an association: compared to those not diagnosed with AIDS, those diagnosed with AIDS were less likely to have disclosed their condition to relatives but more likely to have disclosed it to co-workers.

\section{REACTIONS TO HIV STATUS DISCLOSURE AND LIKELIHOOD OF DISCLOSURE}

Respondents who disclosed their HIV status to people close to them experienced for the most part very supportive reactions. Table 3 shows that, on average, reported reactions were on the top $20 \%$ of the Likert scales, thus indicating high level of acceptance as opposed to rejection. Among those who had not disclosed their status, the reaction they anticipated from members of their social environment was less favorable, with scores ranging from 2.92 (rejection) for non-gay identified respondent's anticipated reactions from friends, to 7.45 for mothers of gays. The likelihood of these respondents disclosing their status in the future varied significantly according to whom the disclosure might be made. Again, more respondents anticipated disclosure to co-workers.

\section{DISCUSSION}

This was the first study to use RDS for the recruitment of MSM in Argentina. It offered the rare opportunity of enrolling a significantly larger number of non-gay 


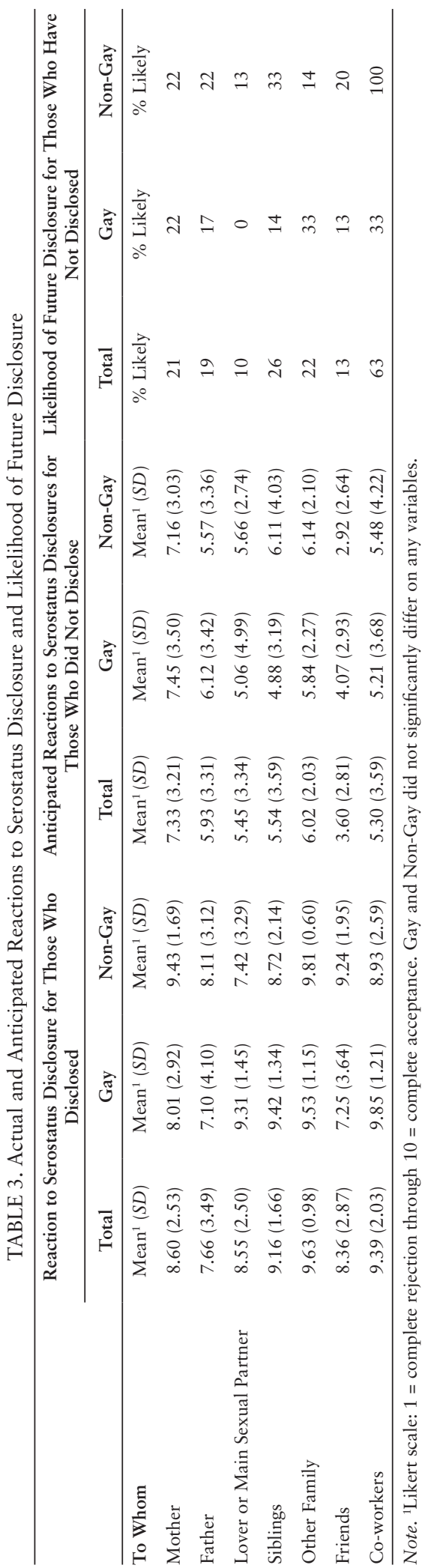


identified and lower SES MSM than those who participated in prior MSM studies in Argentina (Carballo-Diéguez et al., 2011). From this sample, we were able to select a subsample of HIV infected MSM who can be assumed to be more diverse than infected MSM recruited directly from clinics and hospitals.

Disclosure of serostatus was high in this population, particularly to co-workers, non-direct family members and main sexual partners. It is understandable that, in the case of the latter, the closeness of a relationship may facilitate disclosure. Concerning co-workers, the increasingly more liberal sociopolitical climate of the country may support disclosure. It is surprising that disclosure to co-workers was more frequent than to mother and siblings, maybe reflecting that in middle-aged populations extended work hours may create strong bonds allowing the sharing of very personal information. This seems to indicate that the work environment could be fertile for HIV prevention campaigns, particularly those promoting testing even among those who do not consider themselves at risk; also, campaigns to decrease HIV-related stigma could probably be carried out in work environments and through labor unions.

Whenever respondents disclosed their status, they experienced remarkably high levels of support from people in their social milieu. Those who had not disclosed anticipated receiving less support, especially from friends. Maybe those respondents anticipated that disclosing HIV infection 30 years into the epidemic may make them subject to the judgment that "they should have known better" and taken precautions.

High levels of disclosure do not appear to be motivated by the presence of visible symptoms. With rare exceptions, our respondents reported experiencing good to excellent health despite the fact that the majority did not have health insurance. The provision of free HIV medication in Argentina paired with assistance through public hospitals may be an explanation for this remarkable situation.

Likelihood of future disclosure of HIV status was low, except for disclosure to co-workers. Yet, this result may be inflated by the high proportion (but small number) of non-gay identified MSM who anticipated disclosing to co-workers. HIVrelated stigma and fear of being labeled homosexual may be at play among those not disclosing their serostatus. These issues could be addressed at the time of informing someone about his or her HIV-test results, presenting vignettes about people who feared disclosure but ending up experiencing a supportive response from people in their social environment.

In sum, HIV disclosure among infected respondents was high and social support was good. If these outcomes were widely known, individuals who do not disclose their status out of fear of rejection may be further encouraged to discuss their serostatus with coworkers, friends and family.

Eight of the respondents assumed they were infected but their blood tests showed they were HIV-antibody negative. Whereas the opposite situation in which men who assume to be uninfected find out they are infected, is common, our finding was unexpected. At the time of this study, rapid HIV tests were not routinely used in Buenos Aires. Therefore, false positive results cannot be attributed to rapid screening techniques. Men who erroneously assume to be infected may be subject to an unnecessary psychological burden that could be alleviated by knowledge of their true status. Furthermore, the situation shows a failure of engagement in treatment, because retesting of individuals prior to entry in treatment would have led to identification of mistakes. False positive HIV results, whether stemming from erroneous provider information or patient interpretation, require further study. 
Our results should be taken with caution. The small number of HIV-infected respondents in the study offers small statistical power to explore in detail some potential differences. Furthermore, our quantitative research methods did not allow us to explore in more detail situations like the false positive reports.

Nevertheless, within these limitations, our study seems to indicate that the social conditions for HIV status disclosure in Argentina are favorable. This is an encouraging finding.

\section{CONCLUSION}

Argentina has made significant strides in the support of sexual diversities' rights. This seems to result in benefits in different areas, as shown by the remarkable likelihood of PLWH sharing their status with members of their social environment. Making better known the support and positive responses they receive when disclosure takes place may encourage others to come out and reveal their status.

\section{REFERENCES}

Bairan, A., Taylor, G. A., Jones, B., Barbara, J., Akers, T., Sowell, R., \& Mendiola, R. (2007). A model of HIV disclosure: Disclosure and types of social relationships. Journal of the American Academy of Nurse Practitioners, 19(5), 242-250. doi:10.1111/j.17457599.2007.00221.x

Bird, J. D. P., \& Voisin, D. R. (2011). A conceptual model of HIV disclosure in casual sexual encounters among men who have sex with men. Journal of Health Psychology, 16, 365-373. doi:10.1177/1359105310379064

Carballo-Diéguez, A. (1998). The challenge of staying HIV-negative for Latin American immigrants. Journal of Gay \& Lesbian Social Services, 8, 61-82. doi:10.1300/ J041v08n01_05

Carballo-Diéguez, A., Balan, I., Marone, R., Pando, M. A., Dolezal, C., Barreda, V., et al. (2011). Use of respondent driven sampling (RDS) generates a very diverse sample of men who have sex with men (MSM) in Buenos Aires, Argentina. PLoS ONE, 6, e27447. doi:10.1371/journal. pone. 0027447

Fekete, E. M., Antoni, M. H., Lopez, C. R., Durán, R. E., Penedo, F. J., Bandiera, F. C., et al. (2009). Men's serostatus disclosure to parents: Associations among social support, ethnicity, and disease status in men living with HIV. Brain, Behavior, and Immunity, 23, 693-699. doi:10.1016/j. bbi.2009.01.007

Garro, A. M. (1993). Nine years of transition to democracy in Argentina: Partial failure or qualified success. Columbia Journal of Transnational Law, 31, 1-102.
Goel, S., \& Salganik, M. J. (2010). Assessing respondent-driven sampling. Proceedings of the National Academy of Sciences, 107, 6743-6747. doi:10.1073/ pnas. 1000261107

Heckathorn, D. D. (1997). Respondent-driven sampling: A new approach to the study of hidden populations. Social Problems, 44, 174-199.

Heckathorn, D. D. (2002). Respondent-driven sampling II: Deriving valid population estimates from chain-referral samples of hidden populations. Social Problems, 49, 11-34.

Kalichman, S. C., DiMarco, M., Austin, J., Luke, W., \& DiFonzo, K. (2003). Stress, social support, and HIV-status disclosure to family and friends among HIV-positive men and women. Journal of Behavioral Medicine, 26, 315-332. doi:10.1023/A:1024252926930

Mason, H. R., Marks, G., Simoni, J. M., Ruiz, M. S., \& Richardson, J. L. (1995). Culturally sanctioned secrets? Latino men's nondisclosure of HIV infection to family, friends, and lovers. Health Psychology, 14, 6-12.

McKay, T., \& Mutchler, M. G. (2011). The effect of partner sex: Nondisclosure of HIV status to male and female partners among men who have sex with men and women (MSMW). AIDS and Behavior, 15, 11401152. doi:10.1007/s10461-010-9851-4

Nachega, J. B., Morroni, C., Zuniga, J. M., Sherer, R., Beyrer, C., Solomon, S., et al. (2012). HIV-related stigma, isolation, discrimination, and serostatus disclosure: A global survey of 2035 HIV-infected adults. Journal of the International Association of 
Physicians in AIDS Care, 11, 172-178. doi:10.1177/1545109712436723

Obermeyer, C. M., Baijal, P., \& Pegurri, E. (2011). Facilitating HIV disclosure across diverse settings: A review. American Journal of Public Health, 101, 1011-1023. doi: 10.2105/ajph.2010.300102

Pando, M. A., Balan, I. C., Marone, R., Dolezal, C., Leu, C. S., Squiquera, L., et al. (2012). HIV and other sexually transmitted infections among men who have sex with men recruited by RDS in Buenos Aires, Argentina: High HIV and HPV infection. PLOS ONE, 7, e39834. doi:10.1371/journal. pone. 0039834

PASW Statistics (Version 18) (2009). [Computer software]. Chicago, IL: SPSS Inc.

Pecheny, M. (2003). Sexual orientation, AIDS, and human rights in Argentina: The paradox of social advance amid health crisis. In S. Eckstein \& T. Wickham-Crowley (Eds.), Struggles for social rights in Latin America (pp. 253-269). New York: Routledge.

Pulerwitz, J., Michaelis, A. P., Lippman, S. A., Chinaglia, M., \& Diaz, J. (2008). HIV-related stigma, service utilization, and status disclosure among truck drivers crossing the Southern borders in Brazil. AIDS Care, 20, 764770. doi:10.1080/09540120701506796

Salganik, M. J., \& Heckathorn, D. D. (2004). Sampling and estimation in hidden populations using respondent-driven sampling. Sociological Methodology, 34, 193-240. doi:10.1111/j.0081-1750.2004.00152.x

Serovich, J. M. (2001). A test of two HIV disclosure theories. AIDS Education and Prevention, 13, 355-364.

Serovich, J. M., Grafsky, E. L., \& Craft, S. M. (2011). Does family matter to HIV-positive men who have sex with men? Journal of Marital and Family Therapy, 37, 290-298. doi:10.1111/j.1752-0606.2009.00177.x

Serovich, J. M., \& Mosack, K. E. (2003). Reasons for HIV disclosure or nondisclosure to casual sexual partners. AIDS Education and Prevention, 15, 70-80.

Stirratt, M. J., Remien, R. H., Smith, A., Copeland, O. Q., Dolezal, C., \& Krieger, D. (2006). The role of HIV serostatus disclosure in antiretroviral medication adherence. AIDS and Behavior, 10, 483-493. doi:10.1007/ s10461-006-9106-6

Volz, E., \& Heckathorn, D. D. (2008). Probability based estimation theory for respondent driven sampling. Journal of Official Statistics, 24, 79-97.

Waddell, E. N., \& Messeri, P. A. (2006). Social support, disclosure, and use of antiretroviral therapy. AIDS and Behavior, 10, 263272. doi:10.1007/s10461-005-9042-x

Whitam, F. L. (1983). Culturally invariable properties of male homosexuality: Tentative conclusions from cross-cultural research. Archives of Sexual Behavior, 12, 207-226. doi:10.1007/bf01542072

Wohl, A., Galvan, F., Myers, H., Garland, W., George, S., Witt, M., et al. (2011). Do social support, stress, disclosure and stigma influence retention in HIV care for Latino and African American men who have sex with men and women? AIDS and Behavior, 15, 1098-1110. doi:10.1007/s10461-0109833-6

Woodward, E. N., \& Pantalone, D. W. (2012). The role of social support and negative affect in medication adherence for HIV-infected men who have sex with men. Journal of the Association of Nurses in AIDS care, 23, 388396. doi:10.1016/j.jana.2011.09.004

Zea, M. C., Reisen, C. A., Poppen, P. J., Bianchi, F. T., \& Echeverry, J. J. (2007). Predictors of disclosure of human immunovirus-positive serostatus among Latino gay men. Cultural Diversity and Ethnic Minority Psychology, 13, 304-312. doi:10.1037/10999809.13.4.304

Zea, M. C., Reisen, C., Poppen, P., Bianchi, F., \& Echeverry, J. (2005). Disclosure of HIV status and psychological well-being among Latino gay and bisexual men. AIDS and Behavior, 9, 15-26. doi: 10.1007/s10461005-1678-z

Zea, M. C., Reisen, C. A., Poppen, P. J., Echeverry, J. J., \& Bianchi, F. T. (2004). Disclosure of HIV-positive status to Latino gay men's social networks. American Journal of Community Psychology, 33, 107-116. doi: 10.1023/B:AJCP.0000014322.33616.ae 
Copyright of AIDS Education \& Prevention is the property of Guilford Publications Inc. and its content may not be copied or emailed to multiple sites or posted to a listserv without the copyright holder's express written permission. However, users may print, download, or email articles for individual use. 